05.3;09.3

\title{
Нелинейно-оптическая диагностика поликристаллических тонких пленок цирконата-титаната свинца
}

\author{
() А.С. Елшин ${ }^{1}$, И.П. Пронин ${ }^{2}$, С.В. Сенкевич ${ }^{2}$, Е.Д. Мишина ${ }^{1}$ \\ ${ }^{1}$ МИРЭА - Российский технологический университет, Москва, Россия \\ ${ }^{2}$ Физико-технический институт им. А.Ф. Иофрфе РАН, Санкт-Петербург, Россия \\ E-mail: elshin_andrew@mail.ru
}

Поступило в Редакцию 6 декабря 2019г.

В окончательной редакции 24 января 2020г.

Принято к публикации 28 января 2020 г.

\begin{abstract}
С помощью нелинейно-оптической микроскопии изучены однофазные (перовскит) и двухфазные (перовскит+пирохлор) тонкие пленки цирконата-титаната свинца, осажденные на подложки $\mathrm{Pt} / \mathrm{TiO}_{2} / \mathrm{SiO}_{2} / \mathrm{Si}$ методом высокочастотного магнетронного распыления при различных расстояниях мишень-подложка $(D=30-70 \mathrm{~mm})$. Обнаружено неоднородное распределение сигнала второй гармоники в сферолитовых перовскитовых островках, в том числе увеличение сигнала на границе перовскит/пирохлор, которое может быть связано с неоднородным распределением механических напряжений. Обсуждаются причины сильного изменения сигнала второй гармоники, его взаимосвязи с изменением характера сферолитовой структуры и условий осаждения пленок при варьировании расстояния мишень-подложка.
\end{abstract}

Ключевые слова: сегнетоэлектрические тонкие пленки, цирконат-титанат свинца, сферолитовые структуры, нелинейно-оптическая диагностика, генерация второй гармоники.

DOI: 10.21883/PJTF.2020.08.49306.18142

Развитие технологий формирования тонких сегнетоэлектрических слоев цирконата-титаната свинца (PZT) позволяет рассматривать эти материалы как перспективные для создания элементов памяти, пьезоэлектрических преобразователей энергии, микроэлектромеханических устройств, приемников инфракрасного излучения и т.д. [1-6]. Для инкорпорации формируемых тонких слоев PZT (субмикронных или микронных толщин) в КМОП-технологии используются, как правило, кремниевые подложки. Физические свойства пленок определяются составом и микроструктурой, которые в свою очередь зависят не только от материала подложки и подслоев, но и от технологических параметров их осаждения и режимов термообработки. При вакуумном методе получения пленок с использованием высокочастотного магнетронного осаждения такими параметрами являются давление и состав рабочего газа, температура подложки, расстояние от мишени до подложки, температура термообработки и т.д. [7-11]. Для получения достоверной информации о микроструктуре и физических свойствах тонких слоев важно использование различных современных и дополняющих друг друга диагностических методов. К их числу относятся не только рентгеноструктурные методы, методы атомно-силовой микроскопии и электронной микроскопии, но и оптические методы, в том числе метод нелинейно-оптической микроскопии, который является информативным для исследования фазовых переходов с изменением кристаллографической симметрии, кристаллографической ориентации, а также доменных структур [12,13]. В сегнетоэлектриках интенсивность генерации второй гармоники (ГВГ) пропорциональна квадрату средней по лазерному пятну со- ставляющей сегнетоэлектрической поляризации, ориентированной нормально к направлению распространения падающего оптического луча [14].

В настоящей работе метод ГВГ использовался для диагностики тонких пленок PZT с составами, соответствующими области морфотропной фазовой границы, где их диэлектрические и электромеханические параметры достигают максимальных значений $[15,16]$. Пленки осаждались на платинированные кремниевые подложки $\left(\mathrm{Pt} / \mathrm{Ti}\left(\mathrm{TiO}_{2}\right) / \mathrm{SiO}_{2} / \mathrm{Si}\right)$ методом высокочастотного магнетронного распыления керамической мишени при изменении расстояния от мишени до подложки в диапазоне 30-70 mm с шагом $10 \mathrm{~mm}$ при давлении рабочего газа, равном $8 \mathrm{~Pa}$, что позволяло „тонко“ варьировать состав (элементное соотношение атомов $\mathrm{Zr}$ и $\mathrm{Ti}$ ) в пределах $1.5-2 \%$ [17]. Температура последующего отжига, в процессе которого происходило образование фазы перовскита, составляла $580-600^{\circ} \mathrm{C}$. Скорость осаждения при таком изменении расстояния уменьшалась более чем в 2 раза. Время осаждения выбиралось таким образом, чтобы толщина пленок была одинаковой и составляла $500 \mathrm{~nm}$. Для расстояний 30 и $40 \mathrm{~mm}$ исследовались как однофазные перовскитовые пленки, так и пленки, в которых реализовалась двухфазная структура (при меньшей температуре отжига), состоящая из матрицы низкотемпературной фазы пирохлора (Ру) и отдельных перовскитовых (Ре) островков.

С помощью модифицированного конфокального микроскопа WITec alpha 300S были получены нелинейнооптические изображения поверхности образцов. Вторая оптическая гармоника возбуждалась излучением фемтосекундного лазера на кристалле сапфира, допированно- 


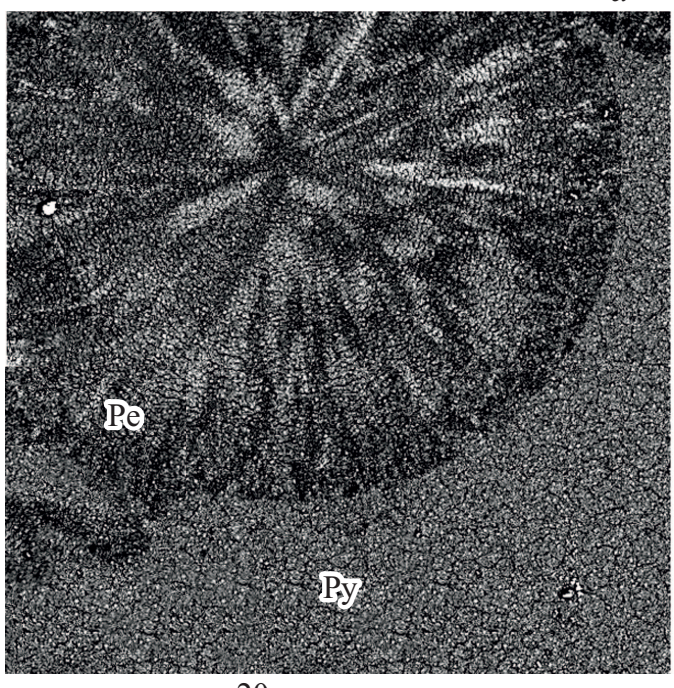

$20 \mu \mathrm{m}$

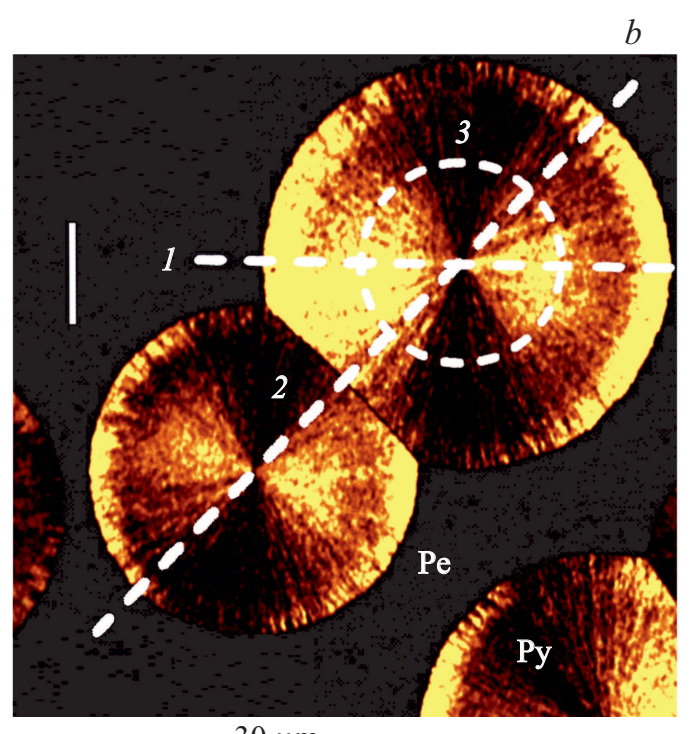

$30 \mu \mathrm{m}$

Рис. 1. РЭМ- $(a)$ и нелинейно-оптические $(b)$ изображения сферолитовых перовскитовых (Ре) островков в пирохлорной (Ру) матрице $(D=40 \mathrm{~mm})$. Штриховыми линиями отмечены сечения $(1-3)$.
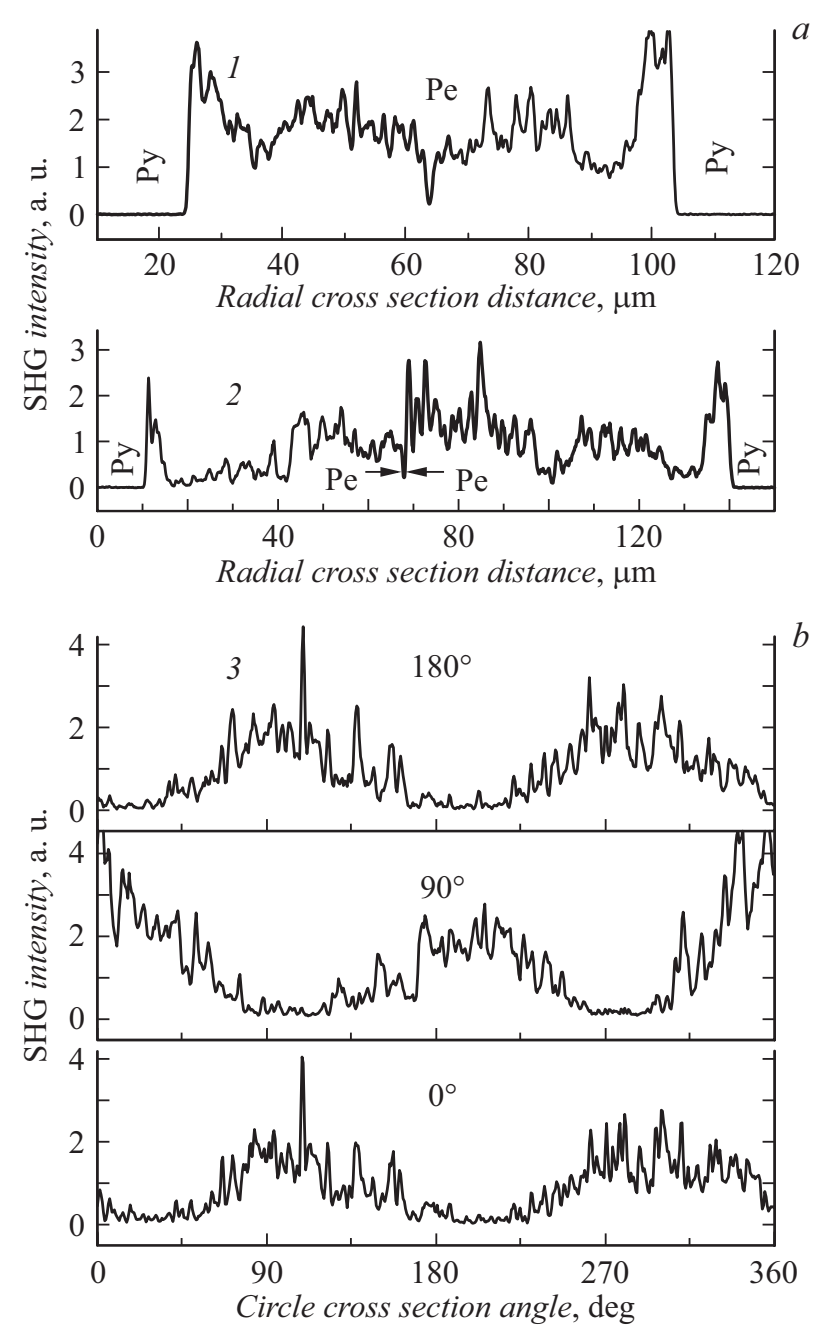

Рис. 2. Распределение сигнала ГВГ по сечению одного (1) и двух (2) сферолитовых островков $(a)$ и по круговому сечению (3) при угле поляризации падающего и отраженного лучей 180,90 и $0^{\circ}(b)$. го ионами титана, с длиной волны $800 \mathrm{~nm}$, частотой повторения $80 \mathrm{MHz}$ и длительностью $100 \mathrm{fs}$. Интенсивность ГВГ на длине волны $400 \mathrm{~nm}$ регистрировалась фотоэлектронным умножителем и системой счета фотонов. Поворот плоскости поляризации падающего луча осуществлялся полуволновой пластинкой перед образцом. В качестве анализатора использовалась призма Глана. Изображения фиксировались в геометрии „на отражение“. Объектив Zeiss N-achroplan 100X, формирующий пятно на образце диаметром $0.9 \mu \mathrm{m}$, и оптическое волокно диаметром $25 \mu \mathrm{m}$ обеспечили пространственное разрешение $\sim 300 \mathrm{~nm}$. Такое разрешение получено потому, что для микроскопии второй гармоники интенсивность сигнала ГВГ пропорциональна квадрату интенсивности падающего луча, что приводит к уменьшению функции размытия точки в $\sqrt{2}$ раз [18]. Электронно-микроскопические изображения структуры были получены на растровом электронном микроскопе (РЭМ) EVO-40 (Zeiss).

На рис. 1 представлены РЭМ- $(a)$ и оптическое на длине волны ГВГ $(b)$ изображения перовскитовых островков. ГВГ-изображение представлено для направления поляризации падающего и отраженного лучей, отмеченного светлой линией. Перовскитовые островки круглой формы характеризовались радиально-лучистой сферолитовой структурой, которая отчетливо наблюдалась как на РЭМ-, так и на ГВГ-изображениях. Видно сильное различие сигнала ГВГ между внутренней и внешней областями островков, о чем свидетельствуют распределения сигнала ГВГ (рис. 2,a) вдоль диаметральных (радиальных) сечений одного (рис. 1, сечение 1) и двух островков (рис. 1, сечение 2). При движении от центра сферолита сигнал ГВГ сначала возрастает, достигает локального максимума примерно на середине радиуса, затем спадает к краю и на расстоянии $\sim 5-7 \mu \mathrm{m}$ до 

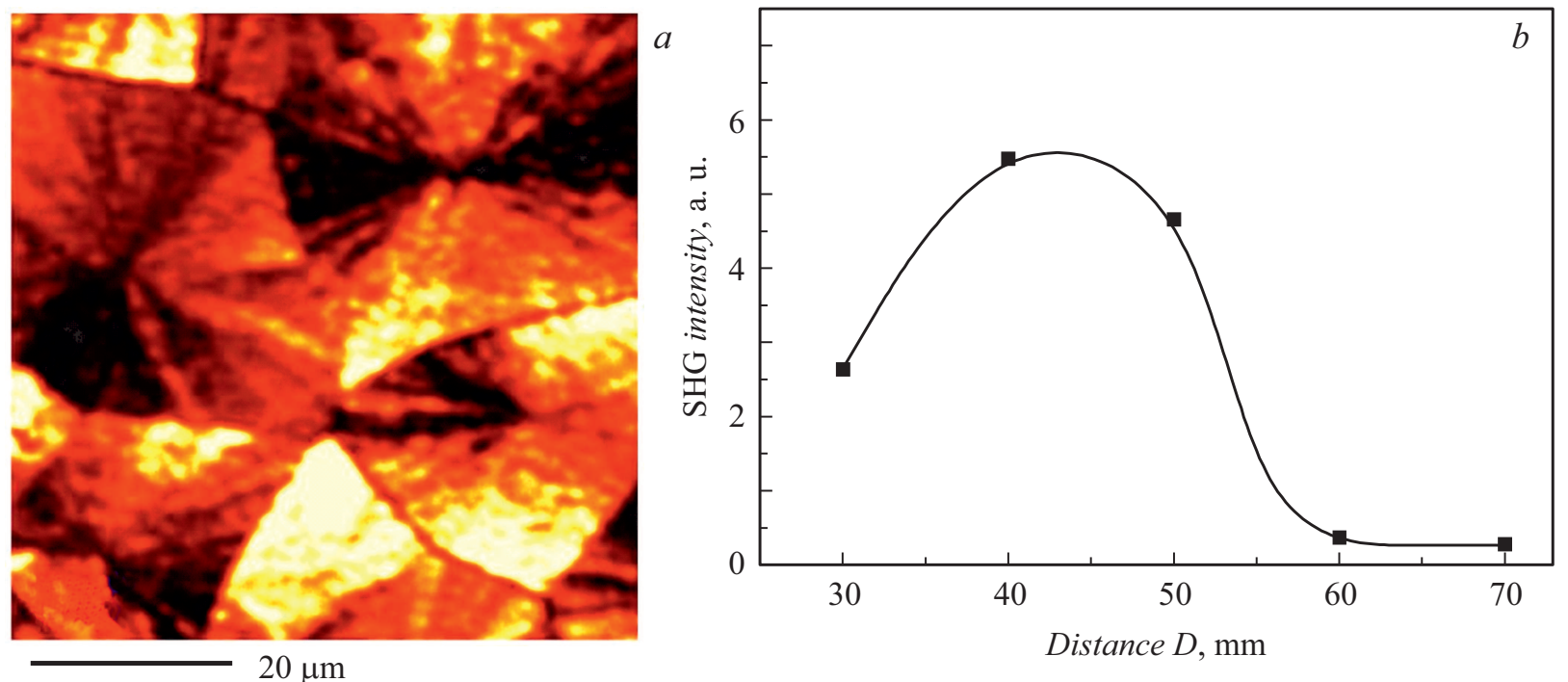

Рис. 3. Нелинейно-оптическое (ГВГ) изображение сплошной перовскитовой тонкой пленки РZT $(D=30 \mathrm{~mm})(a)$ и зависимость интенсивности сигнала ГВГ, усредненного по площади сканирования, от расстояния $D(b)$.

края снова возрастает. Величина сигнала ГВГ возрастает на краях сферолитов в $\sim 2$ раза по сравнению с сигналом в центральной области. Подобное поведение может свидетельствовать о формировании в процессе кристаллизации и рекристаллизации фаз перовскита разной плотности, как это было продемонстрировано в [19]. Усиление сигнала ГВГ на краях наблюдается только на границах сферолитовых структур с областью прекурсора (т.е. вблизи фазовой границы Ру/Ре, рис. 1). Вблизи границы слившихся островков усиления не происходит (сечение 2 на рис. 2, a). Можно предположить, что это усиление связано с неоднородностью распределения механических напряжений в прикраевых областях.

Круговое сечение (сечение 3 на рис. $1, b$ ) сигнала ГВГ сферолитовой структуры при фиксированном направлении поляризации имеет два максимума (рис. 2, b). При повороте входной и выходной поляризации распределение сигнала ГВГ по круговому сечению поворачивается на тот же угол: на рис. 2, $b$ приведено три круговых сечения для трех направлений поляризаций луча. Такое поведение может наблюдаться, если сферолит состоит из множественных радиальных кристаллитов (проросших от единого центра кристаллизации) с лежащей в плоскости пленки компонентой поляризации, которая имеет один и тот же угол с радиальным направлением этого кристаллита. Иными словами, кристаллиты с радиальным направлением, отличающимся на заданный угол, будут иметь такой же угол между направлениями поляризации. Чередование минимумов и максимумов интенсивности сигнала ГВГ согласуется с чередованием кристаллитов моноклинной и тетрагональной фаз [17].

Известно, что сигнал ГВГ может усиливаться в зависимости от величины механических напряжений в среде [20]. Ранее с помощью атомно-силовой микроскопии было показано [21], что вследствие разности плотности фаз рельеф на границах Ре/Ру меняется. Ширина области перехода составила порядка 4-5 $\mu \mathrm{m}$, что согласуется с шириной области усиленного сигнала ГВГ.

На рис. 3, а представлено характерное ГВГ-изображение поверхности образца сплошной пленки сферолитовой микроструктуры. С ростом $D$ величина сигнала ГВГ проходила через максимум и затем резко падала при $D=60-70 \mathrm{~mm}$ (рис. $3, b$ ). Эти изменения, как показано в [17], сопровождаются уменьшением числа радиальных лучиков и увеличением их размера. Возможной причиной низкого сигнала ГВГ может быть образование в микроструктуре с большими однородными областями сегнетоэлектрических доменов с характерным размером, меньшим длины волны оптического излучения.

Изменение свойств структуры при вариации расстояния от мишени до подложки может быть связано с особенностями окисления распыленных атомов мишени в процессе осаждения пленок, поскольку, как показали эксперименты, температура подложки за счет разогрева аргоно-кислородной плазмы снижалась от $160^{\circ} \mathrm{C}$ при $D=30 \mathrm{~mm}$ до $90^{\circ} \mathrm{C}$ при $D=70 \mathrm{~mm}$. По всей видимости, уменьшение температуры подложки приводило наряду с увеличением длительности осаждения к увеличению вероятности доокисления свинца до четырехвалентного $\left(\mathrm{PbO}_{2}\right)$ состояния, большей однородности состава по площади и объема осажденной пленки [22] и, как следствие, к иному характеру кристаллизации фазы перовскита.

Таким образом, результаты исследования структуры и свойств тонких пленок PZT, осажденных при различных расстояниях от мишени до подложки $(30-70 \mathrm{~mm})$, позволяют сделать следующие выводы.

1. Выявлена корреляция изображений сферолитовой перовскитовой структуры тонких пленок, полученных методами ГВГ и РЭМ. Предполагается, что радиальное 
изменение интенсивности сигнала ГВГ связано с изменением плотности перовскитовой фазы в процессе ее кристаллизации из фазы пирохлора и ее рекристаллизации в более плотную модификацию.

2. Изменение расстояния от мишени до подложки в процессе осаждения тонких пленок приводило к резкому изменению плотности радиальных лучиков и сигнала ГВГ. Причиной таких изменений могут являться изменения температуры разогрева подложки газовой плазмой и длительности осаждения, приводящих к изменению условий окисления, а при последующем отжиге - к изменению параметров и механизмов кристаллизации фазы перовскита.

\section{Финансирование работы}

Работа выполнена в рамках госзадания, проект № FSFZ-2020-0022 (Е.Д.М.), а также гранта для молодых ученых РТУ МИРЭА № НИЧ-43 (А.С.Е.).

\section{Конфликт интересов}

Авторы заявляют, что у них нет конфликта интересов.

\section{Список литературы}

[1] Воротилов К.А., Мухортов В.М., Сигов А.С. Интегрированные сегнетоэлектрические устройства. М.: Энергоатомиздат, 2011. $175 \mathrm{c}$.

[2] Hwang G.T., Annapureddy V., Han J.H., Joe D.J., Baek C., Park D.Y., Kim D.H., Park J.H., Jeong C.K., Park K.I., Choi J.J., Kim D.K., Ryu J., Lee K.J. // Adv. Energy Mater. 2016. V. 6. N 13. P. 1600237 . DOI: 10.1002/aenm.201600237

[3] Yeo H.G., Ma X., Rahn C., Trolier-McKinstry S. // Adv. Funct. Mater. 2016. V. 26. N 32. P. 5940-5946. DOI: $10.1002 / \mathrm{adfm} .201601347$

[4] Muralt P. // J. Am. Ceram. Soc. 2008. V. 91. N 5. P. 1385 1396. DOI: $10.1111 / \mathrm{j} .1551-2916.2008 .02421 . x$

[5] Muralt P. // Rep. Prog. Phys. 2001. V. 64. N 10. P. 1339-1388. DOI: 10.1007/0-387-23319-9_5

[6] Scott J.F. // Science. 2007. V. 315. N 5814. P. 954-959. DOI: $10.1126 /$ science. 1129564

[7] Iijima K., Ueda I., Kugimiya K. // Jpn. J. Appl. Phys. 1991. V. 30. Pt 1. N 9B. P. 2149-2151.

[8] Suu K., Masuda T., Nishioka Y., Tani N. Process stability control of $\mathrm{Pb}(\mathrm{Zr}, \mathrm{Ti}) \mathrm{O}_{3}$ ferroelectric thin film sputtering for FRAM application // Proc. of the Eleventh IEEE Int. Symp. on applications of ferroelectrics (ISAF XI'98). Montreux, Switzerland, 1998. P. 19-22.

[9] Alrashda M.H.S., Hamzah A.A., Majlis B.Y. RF sputtered PZT thin film at MPB for piezoelectric harvester devices // 2015 IEEE Regional Symp. on micro and nanoelectronics (RSM). IEEE, 2015. P. 1-4. DOI: 10.1109/RSM.2015.7355018

[10] Mukhin N.V., Chigirev D.A. // J. Phys.: Conf. Ser. 2017. V. 872. P. 012045. DOI: $10.1088 / 1742-6596 / 872 / 1 / 012045$

[11] Osipov V.V., Kaptelov E.Yu., Senkevich S.V., Kiselev D.A., Pronin I.P. // Ferroelectrics. 2018. V. 535. N 1. P. 78-82. DOI: $10.1080 / 00150193.2018 .1432931$
[12] Denev S.A., Lummen T.T., Barnes E., Kumar A., Gopalan V.// J. Am. Ceram. Soc. 2011. V. 94. N 9. P. 2699-2727. DOI: $10.1111 / \mathrm{j} .1551-2916.2011 .04740 . \mathrm{x}$

[13] Буряков А.M. // Рос. технол. журн. 2017. Т. 5. № 2. С. 22 31. DOI: $10.32362 / 2500-316 X-2017-5-2-22-31$

[14] Dolino G., Lajzerowicz J., Vallade M. // Phys. Rev. B. 1970. V. 2. N 6. P. 2194-2200. DOI: 10.1103/PhysRevB.2.2194

[15] Яфбе Б., Кук У., Яфбе Г. Пьезоэлектрическая керамика. М.: Мир, 1974. 288 c.

[16] Noheda B., Cox D.E. // Phase Trans. 2006. V. 79. N 1-2. P. 5-20. DOI: $10.1080 / 01411590500467262$

[17] Pronin V.P., Dolgintsev D.M., Osipov V.V., Pronin I.P., Senkevich S.V., Kaptelov E.Y. // Mater. Sci. Eng. 2018. V. 387. N 1. P. 012063.

[18] Gauderon R., Lukins P.B., Sheppard C.J.R. // Opt. Lett. 1998. V. 23. N 15. P. 1209-1211. DOI: 10.1364/OL.23.001209

[19] Пронин И.П., Каптелов Е.Ю., Сенкевич С.В., Климов В.А., Зайщева Н.В., Шаплыгина Т.А., Кукушкин С.А. // ФTT. 2010. T. 52. B. 1. C. 124-129. DOI: $10.1134 / \mathrm{S} 1063783410010233$

[20] Bertocchi M., Luppi E., Degoli E., Véniard V., Ossicini S. // J. Chem. Phys. 2014. V. 140. N 21. P. 214705. DOI: $10.1063 / 1.4880756$

[21] Пронин И.П., Каптелов Е.Ю., Сенкевич С.В., Киселев Д.А., Осипов В.В., Пронин В.П. // ФТТ. 2019. Т. 61. B. 12. C. 2369-2374. DOI: 10.1134/S1063783419120424

[22] Тентилова И.Ю., Кукушкин С.А., Каптелов Е.Ю., Пронин И.П., Уголков В.Л. // Письма в ЖТФ. 2011. Т. 37. В. 4. C. 37-43. DOI: $10.1134 / \mathrm{S} 1063785011020295$ 